Review

\title{
Cultural Perceptions of Human Intelligence
}

\author{
E.A. Cocodia \\ University of Notre Dame Australia, Broadway 104, NSW, 2007, Australia; \\ E-Mail: Ebinepre.cocodia@nd.edu.au; Tel.: +61-02-8204-4103 \\ External Editor: Paul De Boeck
}

Received: 11 August 2014; in revised format: 19 November 2014 / Accepted: 2 December 2014 / Published: 18 December 2014

\begin{abstract}
This paper analyzes notions of culture and human intelligence. Drawing on implicit and explicit theory frameworks, I explore discourses about perceptions of intelligence and culture. These include cultural perceptions and meanings of intelligence in Asia, Africa and Western cultures. While there is little consensus on what intelligence really means from one culture to the next, the literature suggests that the culture or sub culture of an individual will determine how intelligence is conceived. In conclusion, the view is that culture and intelligence are interwoven.
\end{abstract}

Keywords: Africa; Asia; behavior; culture; intelligence; IQ

\section{Introduction}

Implicit theories of intelligence may vary from one culture to another. Extensive research on culture and intelligence has been conducted [1-3] with some significant results. What does culture mean in this context? Culture is the entire way of life of a group of people including their language, food, social organization, education, and childrearing practices. Ogbu [4] noted that culture consists of four main concepts. The first include the "customary behaviors" of a group of people. Hence it includes ways a group celebrates new life or mourns their dead or even the way that childrearing practices are conducted. This is not an exhaustive description as culture embraces all aspects of community life. Ogbu described the second as cultural "code" or the process whereby their expectations, emotions and assumptions are displayed as a result of customary behaviors. The third is "artifacts" or those things that are of value to a culture. The final concept is a cultural "institution" which includes religion, 
politics, and other social organizations. Culture will, therefore, determine the very nature of intelligence, as it is representative of every facet of an individual's life. Culture may also determine who has what level of intelligence through a process of classification [5]. For this reason, there may be certain concepts that may be appropriate or more valued in one culture and unsuitable in another.

\section{Conceptualizing Intelligence}

In support of the discussion around notions of intelligence from a cultural perspective it is appropriate to explore theories of some experts in the field of intelligence. Thus, intelligence is described as single and/or multiple constructs according to Spearman's $g$ theory, Horn-Cattell-Theory and Sternberg's triarchic theory.

\subsection{Spearman's g Theory}

Intelligence is conceptualized as $g$ where, $g$ refers to general ability or general intelligence based on Spearman's factor analysis of the correlations among a large variety of mental ability measurements [6,7]. Spearman originally proposed a two-factor model, the two factors being the general factor $(g)$ common to all tasks and some factor $(s)$ which are specific to that task and may vary from one intellectual act to another. Predictions of performance on those tasks high in $s$ loadings are not as accurate as those that are high in $g$ loadings. Spearman's research included administering different tests to assess various individuals' cognitive abilities. In examining the results of this variety of tests Spearman established a positive correlation between each person's scores. He found that, for example, a person who achieved high scores on a problem solving test also performed well on a verbal ability test. This correlation on individual test performance is what Spearman referred to as a positive manifold or general intelligence $(g)$. Spearman's finding was based on his empirical investigations of the observed correlation between two variables and the extent to which it misjudges its degree of relationship such that the two variables display inaccurate or unreliable measurement.

Spearman proposed that a better understanding of intelligence can only be accomplished when researchers are able to study the brain at all levels, including all of its features. Conceptualizing intelligence as $g$, a single underlying dimension suggests that the human brain is primarily responsible for all of an individual's intelligent actions and thoughts [7]. $G$ has therefore been described as a biological variable and thus a property of the brain [7].

$G$ is a property which controversially, some researchers [6-8] argue that all human beings possess in varying degrees. Other researchers including pioneers like Binet and Thurstone [9] argue that such a concept $(g)$ is not a valid one. Psychometricians include those who accept the notion of $g$ describing it as the true core of intelligence as it predicts performance to an extent in human behavior that requires learning, decision-making and judgment. Jensen [10] describes intelligence as "the sum total of all mental abilities" emphasizing the importance of the brain in carrying out every day mental tasks which are either intelligent or not. $G$ is described as essential to scholastic achievement, success in the workplace, as well as other real life situations [7,11]. 


\subsection{The Horn-Cattell Theory}

The Horn-Cattell theory of intelligence is defined as fluid or crystallized abilities where fluid intelligence is [12-14] as a purer indicator of ability and crystallized intelligence is defined as intelligence integrated through culture. Hence intelligence is influenced by environmental factors such as education and culture. Cattell [14] however theorized that crystallized is a product of fluid ability. The validity of this has been questioned [15] especially as fluid ability includes non-verbal reasoning abilities (Gf) while crystallized abilities are verbal-educational abilities $(G c)$.

Cattell, a student of Spearman, developed the theories of fluid and crystallized abilities based on Spearman's $g$ theory. Cattell hypothesized that Spearman's $g$ consists of two distinct general factors and not a single factor as proposed by Spearman. He labelled the separate factors as Fluid intelligence and Crystallized intelligence. In an attempt to integrate this theory with that of Spearman's, Cattell's theory focuses on the second-order abilities discovered in various structural analyses as in the Primary Mental Abilities structure. This structural evidence emerged as a result of empirical studies conducted over the years in the area of cognitive abilities. Horn described these cognitive capacities as distinct intelligences. Cattell symbolized fluid intelligence as $G f$ while crystallized intelligence is $G c$.

Cattell described fluid intelligence as that concept which does not depend on education experience or prior knowledge. This he proposed manifests in a wide variety of intellectual activities. Cattell pointed out that fluid intelligence is the ability to solve problems. This suggests that prior knowledge, strategies or skills are not of relevance here as what an individual has stored in memory is not useful. The Horn-Cattell theory proposed that fluid intelligence does not have a specific form. This model also implies that education or experience has no influence on fluid ability. Cattell pointed out that fluid intelligence manifests in those tasks that require an individual to employ high levels of reasoning and to draw inferences as well. Primary Mental Abilities are inclusive of fluid and crystallized intelligence. Researchers have criticized this theory, arguing that $G f$ is actually knowledge dependent [14].

In direct contrast to fluid intelligence, Horn described crystallized intelligence as a product of experience. This theory proposed that crystallized intelligence occurs when fluid intelligence merges with culture [15]. This model suggests that the more knowledge and experience acquired, the higher the levels of crystallized intelligence. Crystallized intelligence is influenced by culture and education. For instance, the ability to make good use of language or solve complex technical problems occurs as a result of crystallized intelligence. The Horn-Cattell model of ability was expanded to include other general factors.

\subsection{Sternberg's Triarchic Theory}

Sternberg [16,17] proposed an information processing perspective in a bid to conceptualize intelligence. The concept of intelligence as an information processing construct suggests that it is purely cognitive in nature. According to Sternberg, intelligence may therefore be gauged on the basis of an individual's speed of information processing. Sternberg's theory emphasizes on a clear and simple form of information processing. The triarchic theory is divided into three aspects with each aspect further split into categories.

The first aspect is the componential subtheory which covers the mechanisms of intelligent functioning. In this category are metacomponents which focus on the way an individual behaves. That is, the kind of behaviors classifiable as intelligent. This may include the way one solves a problem. In addition, in 
this category are performance components which focus on those strategies which an individual uses in the actual process of problem-solving. The last factor are the knowledge-acquisition components which as the name suggest focuses on the process involved in acquiring new information. This sub theory therefore includes the ability to think abstractly and process information successfully.

The second is the experiential subtheory. Here Sternberg proposed that intelligent behavior is interpreted along a continuum of novel to highly familiar tasks or situations. This subtheory therefore emphasizes on the ability to formulate new ideas and combine seemingly unrelated facts and information.

The third aspect is the contextual subtheory which focuses on the sociocultural context in which intelligent behavior occurs. This subtheory is more interested in the connection between intelligence and the individual's world. Thus, Sternberg proposes that intelligent behavior is governed by the level of adaptation to one's environment. This means that the ability to adapt to changing environmental conditions is reflective of intelligent behavior. Sternberg [16] also argued that the ability to utilize the environment to make best use of one's strength and compensate for one's weakness is characteristic of intelligent behavior.

Sternberg's theory lay emphasis on speed of processing information therefore arguing that intelligence is conceptualized in this way. Some researchers have criticized this theory as being extremely broad, suggesting that almost anything imaginable is conceptualized as intelligence [18]. However, Sternberg linked all three sub theories to behavior. Thus, conceptualizing intelligence as behavior. Sternberg also pointed out that intelligent behavior occurs as a result of interaction between all three sub theories. Sternberg argued that general intelligence $(g)$ will determine how efficiently information processing components are utilized. Therefore Sternberg's theory successfully describes a continuum along which individuals can be compared [19].

\section{Cultural Conceptions of Intelligence}

Although the previous sections provide a brief overview of the extensive theoretical work conducted by experts in the field, the evidence indicates that it is not simple to define intelligence as shown by the 1921 symposium on intelligence [20]. In addition, conceptualizing intelligence outside of one's own culture may also prove to be a challenge. Notions of intelligence may vary based on experiences within our social and cultural environment. It should be pointed out that notions of intelligence may differ even within cultures. For instance, it is possible to find strong group differences in conceptions of intelligence within a cultural group. Boas [21] investigated social organization of Native Americans in the Northwest of the USA. Much to his surprise he found that despite sharing a common culture, there was still a lack of uniformity within the cultural group he visited. For instance, language may vary slightly, as did some ceremonies. Another study which is much more relevant to the current review was conducted by Wober [22]. Here, conceptions of intelligence varied within subgroups of tribes in rural Uganda. Some tribes viewed intelligence as inclusive of specific practical skills while cognitive speed was frowned upon. This suggests as some experts propose $[1,4,23]$ that intelligence is a relative construct relying on individual behavioral or mental events which occur at different times or different places.

Cross-cultural studies of intelligence have led to different schools of thought concerning this issue. One is viewed from the Relativists' perspective while the other is the Universalists' school of 
thought $[4,5,23]$. The relativist argues that intelligence is that act which a particular culture defines or values as intelligent. This suggests that intelligence is relative, depending on how different actions are carried out at different times by different groups. This suggests that intelligence will have an indigenous meaning and concept for a particular group of people sharing a common culture. Anastasi [24] argued that it is the combination of abilities that are used for survival and advancement in that culture that should be defined as intelligence in that same environment. This is a relativist point of view. Relativism however does not allow for successful quantitative analysis or measurement of intelligence within a community. Any attempt is likely to cause more harm than good [23] within that community, as interpretation of such measurements may prove to be inaccurate.

Universalism as described by Berry is the direct contrast to relativism. The assumption is that there are universal abilities which all species possess despite cultural differences. Regardless of the environment in which they find themselves humans will possess innate abilities which enable them to carry out tasks that measure intelligence and solve problems. Berry argued that human abilities develop according to "ecological demands". These demands he points out enable individuals to function within a cultural environment. Berry pointed out that all individuals possess common abilities such as spatial abilities and cognitive abilities. These abilities, he points out, develop over time. Berry noted that human beings are species that adapt to suit their environment hence the differences in labelling of those behaviors that are acceptable as intelligent in each culture. These abilities may vary according to individual cultures and environment. However, Berry argued that the development of cognitive styles, spatial abilities and the attainment of Piagetian stages are universal regardless of culture. This suggests that we all possess some common innate abilities which are what experts seek to measure or find when individuals notwithstanding culture are tested.

\subsection{Asian Conceptions of Intelligence}

Eastern conceptions of intelligence are described as rooted in Eastern traditions [25]. Culture and traditions govern perceptions of intelligence in the region. Conceptions of intelligence will vary significantly in Asia as the continent consists of a wide range of cultural differences and beliefs. For instance, India located in South East Asia has over 200 different languages. Hindi is the official language and is also one of the most commonly spoken languages in the world, next to English and Chinese. Some Asian cultures embrace Confucian, Taoist, Hindu and Buddhist philosophies. These philosophies encourage moral and religious attitudes which are reflective of individual behavior, thus intelligence is interwoven with religion and moral behavior [25].

Some South East and East Asian cultures also have many similarities due to their early migratory patterns. The population of this region has been influenced by various southward migrations. This also created different ethnic patterns. Contemporary cultural practices and beliefs in this region indicate that many carry with them the cultural heritage of their Chinese ancestors. Consequently there exists a large native Chinese population in the region. The Taiwanese are examples of such cultural blending. The official language in Taiwan is Mandarin Chinese although pronounced in four distinctive tones. Cantonese, Hokkien, and Teochew are Southern Chinese languages also widely spoken in South East Asia among large populations along with their indigenous languages. There are some countries which share some cultural similarities (such as Singapore, Thailand, Korea) while others differ considerably 
(such as Vietnam, Philippines). As language, food, religion, and total ways of life may vary from one Asian culture to another, as such, notions of intelligence may also vary. These differences on perceptions of intelligence may occur when a particular subgroup conceptualizes certain behaviors as intelligent while another subgroup does not regard such behavior as intelligent. East Asian cultures however do bear some similarities. Confucian, Taoist, Buddhist and Hindu traditions are reflective of Asian cultures since earliest times. Notions of intelligence may therefore be influenced by these traditions. The following section reviews key aspects of these traditions relevant to the current paper.

\subsubsection{Confucian Tradition}

This represents the religio-philosophical traditions that have shaped Chinese life for centuries. It influences to an extent, the actions of individuals within his/her culture. The history of Confucianism goes back to the period of Chinese dynasties. In the Han dynasty (206 B.C. - 219 A.D.) Confucius remained the highest sage and ancient teacher of his era particularly as great strides were taken during this period to develop schools. The academic thought of that dynasty which is known as Confucius' philosophy is at the root of Chinese beliefs till this day. Ancient Chinese culture imbibed Confucianism for more than 2000 years and was included as part of the school curriculum as a course called "Cultivation of the Person". There was however a disruption and exclusion of the teaching of Confucianism from the school curriculum by 1919 after the May 4th Movement in China. As such, Confucianism is hardly visible in organizations and institutions today. It survives only at the most basic level of the popular consciousness and in every day routines [26].

Confucian teachings known as the Confucian Way are documented in six classic books. These books are the Book of Songs, the Book of History (which he edited), the Book of Rites, the Book of Music, the Book of Changes and the Spring and Autumn Annals. Confucian culture is described as impacting on any society which studies his teachings [27]. For instance those who are respectful, polite, grave or prudent are said to display teachings from the Book of Rites; while those who are gentle and honest characterize teachings from the Book of History. Confucianism places huge emphasis on social and class structure in all human relationships. This traditional value is one where respect and obedience for elders prevail and education is described as essential, promoting self-cultivation and self-regulation [28].

In Confucian tradition an intelligent person spends his/her lifetime building his/her character so that he/she can act according to what is right. He/she also expends a great deal of time and effort acquiring knowledge, and enjoying learning throughout his life. The intelligent person practices what he learns through a process of self-cultivation. One is perceived as intelligent when he is able to maintain social relationships. Confucian culture promotes appropriate social behaviors such as politeness, candor, discipline, self-respect, and vocabulary. Within this culture, a scholarly person is highly revered. As the core teachings of Confucius includes self-cultivation and educational attainment, the educated person is perceived as intelligent when compared to the uneducated person. As a result of this education is highly valued in the region. For instance, high school enrolment in Korea has increased significantly from 40.2 percent in 1970 to 77.8 percent in 1997 [29]. Byong-ik, [26] points out that Korean society perceive certain professional people as highly knowledgeable. Teachers, university professors, court judge and high-ranking civil servants are seen as intelligent and are highly regarded. The need for self-cultivation has encouraged many East Asian governments to invest heavily in education. For instance, the Singaporean 
government's expenditure on education increased from \$63 million in 1959 to \$3400 million in 1994 [30]. School enrolments in Singapore have doubled over the past four decades. This may be a reflection of the desire for knowledge also connected to individual cultural beliefs.

\subsubsection{Taoist Tradition}

This is another tradition of East Asia. Taoist tradition describes an intelligent person as one who knows Tao (the true greatness) and can put this into practice, being perceptive and responsive to changes in immediate circumstances. For instance social skills are deemed important in Taoist tradition; as such individuals are expected to conduct themselves appropriately while maintaining suitable relationships. Taoism has found its way into all Asian cultures influenced by China, including Vietnam, Japan and Korea. Taoists perceive life as broad and yielding complimenting the moral focused traditions of Confucianism. Taoist thoughts inspire Chinese culture. Taoist and Confucian traditions share the same ideas about man and society. The difference between both traditions is that Confucianism limits its field of interest to the creation of moral and political systems that form society and the Chinese empire while Taoism views represent more personal preoccupations.

\subsubsection{Hindu and Buddhist Philosophies}

It is generally described as intelligence is Buddhi. Intelligence in these traditions include behaviors such as determination, mental effort, comprehending, knowledge, discrimination, noticing, recognizing and decision- making [25]. The Buddhist philosophies describe intelligence as that which is best used for acquiring knowledge. The assumption is that this true and pure knowledge is acquired through the five senses and five motor organs. Thus, suggesting perception and motor skills are required for gathering knowledge, quite similar to Western conception of intelligence. In Buddhist philosophy intelligence in its purest form is not egoistic in nature or temperamental. This is because a poor temperament is perceived as an impediment to one's ability to assimilate knowledge [25]. One has to be unselfish and considerate to be able to acquire knowledge. Das points out that the Buddhist conceptualizes the purest form of intelligence as occurring within the individual only when he/she has crossed a necessary stage. This Das described as the stage of enlightenment which is characterized by concentration, wisdom, generosity, morality and vigor. At this stage, the individual has to give up any thoughts that are egocentric, letting go of any self-centered thoughts in order to achieve the most untainted form of intelligence (i.e., real knowledge). The individual has to abstain from any unnecessary negative emotions, prejudices, and unfavorable temperamental behavior as this is likely to hinder achievement [25].

With this brief background on Eastern traditions and intelligence it is evident that culture and intelligence are interwoven. One study [31] investigated conceptions of intelligence among Chinese, Malayan and Indian mothers in Singapore. These mothers conceive intelligence to include social interactive behavior, appropriate behavior and cognitive and academic ability. Chen and Chen [32] compared conceptions of Chinese graduates from English and non-English speaking colleges. Both groups describe nonverbal reasoning skills as an important representation of intelligence. Another study [33] found that Mainland Chinese people's conception of intelligence includes the ability to reason logically, adapting to new environments, being creative, accepting new things, being insightful, self-confident, 
energetic, having a good sense of humor and good imagination. This is consistent with Western conceptions of intelligence. A study [34] examined conceptions of intelligence among Taiwanese-Chinese people. This study revealed a structure of multiple intelligences similar to Gardner's multiple intelligence theory [35]. Taiwanese-Chinese people conceive intelligence to include interpersonal intelligence which is empathizing with others as well as the ability to deal with daily matters. Intrapersonal intelligence means one has an individual philosophy on life and does not show off "petty intelligence" [34]. Other characteristics of Taiwanese conception of intelligence include general cognitive ability, intellectual self-effacement, and intellectual self-promotion. This is quite consistent with multiple intelligence theory. Asian conceptions of intelligence generally include social skills cognitive skills and knowledge.

\subsection{Western Conceptions of Intelligence}

As Asian culture is relatively diverse so are cultures of Western countries. Individuals in Scandinavian countries, North American countries and Europe may have a wide range of notions of intelligence. Unfortunately, they have tended to be pigeonholed together as Western conceptions of intelligence. This may not be a reasonable notion. Within Western society there exist larger numbers of "subcultures". For instance, Europeans speak a variety of languages ranging from Belgian to French, Danish, English, Dutch and German. They may also have different cultural values. Thus, conceptions of intelligence within these nations may vary. Western conceptions of intelligence are more historically based. That is, it has evolved as a result of human adaptation to Western culture. Western activity is more technological than other cultures. Due to this technological environment, notions of intelligence may include practical skills and abilities. It is also bureaucratic in nature thus requiring cognitive skills and strategies such as grasping relations and thinking symbolically [36,37]. This suggests that because of the complexities of Western society intelligence is adaptive in nature. Individuals use those skills relevant to everyday life such as inference, abstract reasoning, problem-solving, problem-transfer and decision-making.

Western conceptions of intelligence have been studied extensively [38-40]. For instance a study [40] investigated lay and expert conceptions of intelligence in the USA. This study was conducted by randomly enlisting laypersons at train stations, supermarkets or college premises and asking participants to "fill out" open ended questionnaires about their conceptions of intelligent behavior. The behaviors described by the laypersons were grouped into three characteristics namely: Intelligent, Academically intelligent and Everyday intelligent. The researchers continued their investigation by asking experts in the field of intelligence to rate whether the behaviors listed under each of the three groups are indeed characteristic of an intelligent person. In addition, factor analysis of ratings from 65 respondents' also respected experts in the field of intelligence was conducted. The Americans rated verbal intelligence as important with high loadings showing up for characteristics such as "displays a good vocabulary", and "is verbally fluent". Problem solving abilities such as "able to apply knowledge to problem at hand", "plans ahead", and "makes good decisions" were also rated as important by both experts and laypersons in the United States. The practical intelligence factors also had significant loadings for behaviors such as "displays awareness to world around him/her" and "displays interest in the world at large". Another American study [41] found that older adults in the United States place a huge emphasis on practical aspects of intelligence and also place a great deal of importance on general cognitive ability. Other Western studies 
described cognitive skills, decision-making, problem solving and social skills as characteristics of intelligence $[38,39]$.

\subsection{African Conceptions of Intelligence}

Notwithstanding the popular perception of Africa as continent with a common cultural structure, the continent consists of thousands of ethnic groups and different cultures. Africa is a continent with a diversity of beliefs, language, food, religion and social organization. Although there is a wide variety in language, food, beliefs and social organization, there seems to be some basic similarities and differences in their conceptions of intelligence. For instance, in Western Nigeria the Yoruba people's conception of intelligence is referred to as ogbon or sensible behavior, while Ogbu [36] notes the Ibo subsistent farmers' conception of intelligence differs considerably. While the Yoruba culture emphasize the importance of intelligent and acceptable behavior, the Ibo culture lays more emphasis on specific practical skills. This is because within each culture lies a subculture. Values would differ between subcultures. In Yoruba culture it is expected that ogbon is an attribute which everyone possesses and should (in an ideal situation) exercise regularly. Serpell [42] found that some African communities normally would not separate intelligence from social competence. African communities tend to view intelligence as inclusive of all social relationships. This is rated as highly important in African communities probably because of the extended family system. Rural parents in Africa perceive cognitive ability and social responsibility as being interwoven. In another study, In another study, Serpell [42,43] studied the Chewa people of Eastern Zambia. Their conceptions of intelligence include specific practical skills. He argues that their notions of intelligence may vary from that of Western nations. Chewa adults were asked to rate their children's performance in cognitive tasks. Although the tests were adapted to suit the culture of the Chewa people, Serpell found that the children's scores did not correlate with the adults' notions of intelligence. This suggests that Western notions of intelligence may not correspond to African notions of intelligence.

A study of the Luo people of East Africa [2] found that their notions of intelligence consists of four main concepts: rieko which may be likened to the Western idea of academic intelligence as well as other specific skills; paro, meaning practical thinking; luoro which represents social attributes such as respect, responsibility and consideration; and winjo, for comprehending instruction. Another rural East African study [44] found that cultural factors lead parents to place more emphasis on practical intelligence and less on academic intelligence. Super's [45] research on the people of Western Kenya found that notions of intelligence varied between adults and children. Ngom is a term which is applied to children and is synonymous with good judgement of interpersonal relations, responsibility, the ability to comprehend complex matters quickly, verbal accuracy and speed and cognitive speed as well. Utat is linked to adults and is likened to wisdom, cleverness, unselfishness and inventiveness. Kwelat signifies sharpness or smartness.

\section{Discussion}

The Eastern/Asian, Western and African conceptions of intelligence reviewed above suggest that similarities do exist between cultural groups. They also view cognitive skills and abilities as important descriptors of an intelligent person. Decision-making, verbal accuracy, problem solving skills, perceptual 
skills and inference are all important characteristics of intelligence within these cultures. All three cultures lay emphasis on knowledge as product of intelligence. For instance, Confucian traditions expect one to seek knowledge, cultivate oneself so as to be looked upon as intelligent. This means being perceived as intelligent involves a process of self-cultivation which is the core of the Confucian way. The process of self-cultivation is also continuous in nature [26]. Buddhist traditions also conceptualize knowledge as a product of intelligence. Western and African conceptions of intelligence also include knowledge. All three cultures seek knowledge through environmental experiences. This may be achieved formally or informally by reading educational or religious books, learning in school or at home. Knowledge can be acquired informally through those everyday experiences which are recurrent such as decision-making, abstract reasoning and problem solving.

Social skills are also described as characteristic of an intelligent person in all three cultures [34,39,42]. Interpersonal skills, social attributes, and social relationships are expected to be maintained successfully. For instance, Confucianism describes social relationships as a harmonious relationship between man and man, nature and man and heaven and man [26]. American culture tends to associate a high level of social competence with intelligence. Social intelligence in both African and Asian cultures may be rooted in the family system. Families are usually extended in nature and as such social skill are inculcated in all aspects of family life. The interaction between family members is also an important aspect of culture. This may be why some African and Asian cultures describe social intelligence as highly important $[3,43]$.

However, differences in conceptions of intelligence also may exist. For instance, Western and Asian cultures lay emphasis on the ability to excel academically while rural African communities lean more towards social behaviors and practical ability useful in everyday tasks [44]. In addition, African conceptions such as luo, reiko, ngom and so on are unique to various African cultures. Some of these notions of intelligence have no real equivalent in Western and Asian cultures. Likewise some Western concepts of intelligence remain unfamiliar in African cultures such as speed when completing tasks as required by many IQ tests. This suggests that the different cultural value system of each culture will influence notions of intelligence.

Another major difference is that Asian cultures have conceptions of intelligence which are usually interwoven with religious and philosophical beliefs. This may not be quite as prevalent with Western and Africa conceptions of intelligence. For instance, Buddhist philosophical traditions and beliefs describe one's temperament as a vital part of knowledge acquisition and intelligence. Asian culture is also more concerned with the individual's self-improvement. The individual is expected to constantly work on trying to improve one's self. Das [25] noted that this may be linked to the continuous search for knowledge and individual self-fulfillment. Intelligence is also associated with morality in Asian cultures. In Western and African cultures morality tends to be a separate concept from intelligence. Thus, indicating that there are significant differences across the cultures reviewed.

Table 1 provides a summary of conceptions of intelligence within all three cultures. Based on the above review Section I have grouped these into the following: cognitive skills and abilities; social skills; and religious/philosophical/traditional/beliefs. Noticeably, there are fewer asterisks in the African column. However, it does not indicate that these concepts are not present in African culture. Rather a scan of the existing literature indicates that relevant studies are lacking. 
Table 1. Overview of implicit theories of intelligence in Asian, African, and Western cultures.

\begin{tabular}{|c|c|c|c|}
\hline Descriptor & Asian & African & Western \\
\hline \multicolumn{4}{|l|}{ Cognitive Skills and Abilities } \\
\hline Perception and motor skills are required for gathering knowledge & $*$ & & $*$ \\
\hline Nonverbal reasoning skills are highly valued & $*$ & & $*$ \\
\hline Multiple intelligence exists within each individual & * & & * \\
\hline Knowledge is a product of intelligence & * & * & * \\
\hline Speed when completing tasks is highly valued & & & $*$ \\
\hline Grasping relations and thinking symbolically & $*$ & $*$ & $*$ \\
\hline $\begin{array}{l}\text { Inference, abstract reasoning, problem-solving, problem-transfer and } \\
\text { decision-making are highly valued skills }\end{array}$ & & & $*$ \\
\hline Lifelong Learning & $*$ & & \\
\hline \multicolumn{4}{|l|}{ Social Skills } \\
\hline Intelligent person builds character & * & & \\
\hline Able to maintain social relationships & $*$ & & $*$ \\
\hline Self-cultivation is evident & * & & \\
\hline $\begin{array}{l}\text { Interpersonal skills, social attributes, and social relationships are } \\
\text { expected to be maintained successfully }\end{array}$ & * & & * \\
\hline Display social behavior and practical abilities useful in everyday tasks & * & $*$ & $*$ \\
\hline \multicolumn{4}{|l|}{ Religious/philosophical/traditional beliefs } \\
\hline Intelligence is interwoven with religion and moral behavior & $*$ & & \\
\hline
\end{tabular}

\section{Implications for IQ and Intelligence Testing}

Based on the review of notions of intelligence and culture it is evident that there are implications for IQ and intelligence testing. Since Galton's earliest development in the field of IQ testing many other psychometric tools have emerged. These include the Stanford-Binet scale, the Army Alpha and Army Beta tests and Wechsler scales and Raven's Progressive Matrices. Raven's nonverbal intelligence tests are described as the best available measure of general intelligence [46]. The Raven tests consist of the Standard Progressive Matrices, the Colored Progressive Matrices for children and the Advanced Progressive Matrices for adults with higher IQs. Raven's tests are based on spatial analogies. The test requires one to form relations among abstract items. The Raven test is a paper and pencil test, comprising of multiple choices. It consists of 60 matrices or designs, with each having a part missing. The examinee has to select the part which they think is missing from six or eight given options. The Raven's tests can be administered to large or small groups at the once. There is no need for verbal communication between examiner and examinee, as the tasks do not require verbal communication to occur. The test does not require speed in completion of tasks. Hence there is no time limit when taking the test.

There are assertions that intelligence tests such as the Raven's matrices are culturally fairer (or culture reduced). A culture fair test is described as that which is less culture specific. This implies that a culture fair test should accurately provide scores that reflect the ability of the examinee regardless of their cultural background. In order to achieve this, the content of such a test should include items which are familiar to more than one culture. Culturally loaded tests may contain items from everyday experience. They may contain items requiring vocabulary and arithmetic skills. On the other hand, culture reduced tests like the Raven's matrices consist of items which are nonverbal requiring abstract 
reasoning thereby reducing the culture loading of the test. Greenfield [47] argued that a culture fair test should contain items that require responses which are universal. This suggests that the examinee's response should be universally similar regardless of culture or ethnic group. Greenfield also noted the importance of accurate translations of tests to the language of the examinee. This, Greenfield pointed out, may assist in ensuring that IQ tests are culture reduced. Others researchers $[46,48]$ also listed the Raven's tests as an example of a culture reduced test. However, Scarr $[49,50]$ argued that culturally reduced tests like the Raven Matrices may appear to be fair to all cultures but are actually not entirely so. Scarr pointed out that all IQ tests should assess knowledge and skills acquired irrespective of the culture loading of such tests. Scarr argued that limiting examinees to items like the Raven which requires abstract reasoning does not necessarily assist in fully assessing individual ability. In contrast to this line of argument, Anastasi pointed out that it is impossible to totally remove the culture loading of a test as this eliminates the validity of the test. There is some consensus among experts that intelligence tests such as the Raven's are suitable culture reduced test that minimizes the likelihood of culture bias $[46,47,48]$.

Another pertinent issue is whether IQ tests are culturally biased. Cultural bias is a factor that has caused some division in the field of intelligence testing. Scarr [49] described cultural bias as occurring because the assumption is that everyone can access the knowledge and skills being sampled by IQ tests. She argued that there are sub-cultural differences in lifestyles and child rearing practices that may affect equal access to the skills and knowledge required by IQ tests. An implication is that tests should be administered to people of non-Western cultures only if they are appropriate for them [47,51].

Bias in testing gained significantly publicity since the 1970s. For instance, the United States courts reached up to eight decisions restricting the use of tests on minorities [52]. In addition, during this period the Association of Black Psychologists went to court seeking a moratorium to put an end to the testing of minority students in certain states mainly for educational placement. There were also other publicized court cases. The courts' decision on cases such as these led to varied opinions, with some experts arguing that intelligence tests are not biased and culture-fair tests do exist.

The presence of extraneous factors is listed as responsible for bias in testing. This suggests that those factors which do not form part of the test content are to blame for bias in testing. Unequal educational opportunities, teacher expectancy, level of aspiration are some of the factors held to blame for bias in testing [47]. Issues such as practicing or coaching for tests, examinee's test anxiety and motivation (or lack of) to achieve are also described as responsible for test bias [52,53]. Other factors listed include the personality of examiner or examinee, the language of examiner, scoring bias, race, sex and language of both examiner and examinee and content of the test may also create a problem for some examinees [46]. Concepts may also be foreign to examinees thereby creating bias [49]. Scarr pointed out that it is necessary that instructions are clearly communicated before a test is administered. However, there are tests where language or communication issues are eliminated as a cause of bias. Tests exist that do not require examiner and examinee to communicate. Speed is another factor that may cause bias in mental testing as rural cultures may not always believe time is of essence. In contrast, those from the more cosmopolitan or industrialized settings may view speed as an important factor. Psychometrics has addressed this issue by allowing unlimited time when taking certain tests such as the Raven's Matrices. However, many researchers argue that such intelligence tests do not entirely eliminate cultural bias [54]. 
There are two main points I argue in support of IQ testing from a cultural perspective. First, it is evident that IQ tests do measure intelligence by judging how much knowledge has been acquired. Anderson [55] pointed out that assessing knowledge occurs with the aid of specific processors with the speed of these processors being measured, establishing that the function of general intelligence is exercised. This indicates that it is difficult to separate knowledge and intelligence and as such IQ tests are not devoid of knowledge. There is an association between how a person answers questions on an IQ test and their knowledge base. For instance, micro level cognitive tasks like the encoding of alpha-numeric stimuli does require knowledge. Many IQ tests also require problem solving ability to be employed. Scribner [56] pointed out that contrary to initial assumptions that problem solving can be tackled with little or no previous knowledge, it does require some level of subject matter knowledge. Hence complexity and abstraction are also characteristics of intelligence and intelligence requires effective use of knowledge [52]. This specifies the importance of prior learning and knowledge in intelligent behavior.

Second, culture-fair tests which have been highly criticized are actually intended to eliminate key cultural concepts as well as language which an individual relate to. More culturally fair tests include Leiter scales, Raven's Progressive Matrices and the Culture Fair Intelligence Test. However, the Raven's Progressive matrices is the most widely used culture fairer test, although it too has its flaws. Anastasi [48] argued that it is not possible for one test to fit all cultures; therefore, no test can be equally fair to all cultures. She pointed out that cultural influence would and should be reflected in test performance as it is intertwined with behavior. This supports Anastasi's [54] conception of intelligence as a quality of behavior. This suggests that intelligence as a feature of behavior cannot be separated from culture. Behaviors may vary from one culture to the next and as such whatever behavior is normally exhibited in one cultural may be non-existent in another. Some concepts do have to differ in each culture. For instance, in Western cultures, there are usually four seasons: winter, spring, summer and fall. However, in many African countries there are two seasons: rainy and dry. The fruits eaten may also differ. Many African nations do not grow apples and grapes due to climatic conditions. These concepts may therefore be outside the reserve of knowledge that some examinees from the region may be familiar with. This does not suggest that culture-fair tests are not useful. Although they do not fully eliminate the presence of culture on test items, tests are constructed so they are common to different cultures. We cannot have a completely culture-free test as the culture loading of a test determines the validity of the test $[10,14,46]$. This is because the decisive factor of many of these tests would be its culture loading [48].

\section{Conclusions}

Various conceptions of intelligence demonstrate that implicit and explicit theories of intelligence developed over many years help us to form individual conceptions of intelligence. Experts and laymen develop notions of intelligence with some of these notions eventually becoming explicit theories of intelligence. The cultural definitions of intelligence reviewed suggest that there is little agreement on what intelligence is. Like many complex concepts in psychology, researchers in the field are still unable to collectively define intelligence. However, theoreticians have been able to develop conceptual frameworks with many theories complimenting one other. For instance, the Horn-Cattell [12,13] theory 
of fluid and crystallized intelligence can be linked to factorial work developed by Spearman [6] and Thurstone's [9] theories of intelligence. In addition, Sternberg's triarchic theory provides a significant platform for existing research. In addition, such theories propose an association between culture, environment and biological factors. Some frameworks such as Gardner's [35] multiple intelligence theory for example are developed out of the theorists' goal to replace existing theories of intelligence. Whether this proves successful or not is another case. Conceptualizing intelligence as behavior includes the culture and environment of an individual. This suggests that intelligent behavior is in part due to cultural influences as well as the accumulation of knowledge.

Significantly, it is evident that culture, IQ and intelligence testing will continue to be highly debated concepts. Although some critics of Berry's universalism theory have described it as being too broad, it is of particular relevance to the current paper. The idea is that human beings are a species that adapts to suit their environment. This may account for clear differences in labelling of those behaviors, which are accepted as intelligent within each culture. Berry argued that the development of cognitive styles, spatial abilities and the attainment of Piagetian stages are universal regardless of culture. Thus, the argument is that we all possess some common innate abilities, which the experts seek to measure (or identify) when individuals notwithstanding culture are tested.

A review of relevant literature on intelligence and culture indicate that intelligence and culture are interwoven. The culture or sub culture of an individual will determine how one conceives intelligence. A survey of Asian conceptions of intelligence showed how conceptions of intelligence in the East are governed by traditions such as Confucianism and Buddhism. Western conceptions have evolved due to the nature of Western environments that are both complex and technological. African traditions are shown to have notions like luo and ngom consistent of factors unique to certain African cultures. In comparing the three cultures, it is evident that they do share similarities such as conceptualizing knowledge and social skills as products of intelligence. All cultures also conceptualize intelligence to include cognitive abilities. The Asian cultures however differ in that religion, morality and traditions are interwoven with conceptions of intelligence as indicated in Confucian and Buddhist traditions.

\section{Conflicts of Interest}

The author declares no conflict of interest.

\section{References}

1. Nisbett, R.E. Intelligence and How to Get It: Why Schools and Cultures Count. Contemp. Sociol. 2010, 39, 391-396.

2. Grigorenko, E.L.; Geissler, P.W.; Prince, R.; Okatcha, F.; Nokes, C.; Kenny, D.A.; Bundy, D.A.; Sternberg, R.J. The organization of Luo conceptions of intelligence: A study of implicit theories in a Kenyan village. Int. J. Behav. Dev. 2001, 25, 367-378.

3. Azuma, H.; Kashiwagi, K. Descriptors of an intelligent person: A Japanese study. Jpn. Psychol. Res. 1987, 29, 17-26.

4. Ogbu, J.U. Culture and intelligence. In Encyclopaedia of Human Intelligence; Sternberg, R.J., Ed.; Macmillan: New York, NY, USA, 1994; Volume 2, pp. 328-338. 
5. Sternberg, R.J.; Detterman, D. (Eds.) What is Intelligence? Contemporary Viewpoints on Its Nature and Definition; Ablex: Norwood, MA, USA, 1986.

6. Spearman, C. General intelligence objectively determined and measured. Am. J. Psychol. 1904, 15, 201-292.

7. Jensen, A.R. The g Factor: The Science of Mental Ability; Praeger: Westport, CT, USA, 1998.

8. Eysenck, H.J. Personality, Genetics and Behaviour; Praeger: New York, NY, USA, 1982.

9. Thurstone, L.L. Multiple factor analysis. Psychol. Rev. 1931, xxxvui, 406-427.

10. Jensen, A.R. Process differences and individual differences in some cognitive tasks. Intelligence 1987, 11, 107-136.

11. Gottfredson, L.J. Why g matters: The complexity of everyday life. Intelligence 1997, 24, 79-132.

12. Cattell, R.B. Theory of fluid and crystallized intelligence: A critical experiment. J. Educ. Psychol. 1963, 154, 1-22.

13. Horn, J.L. Theory of fluid and crystallized intelligence. In Encyclopaedia of Human Intelligence; Sternberg, R.J., Ed.; Macmillan: New York, NY, USA, 1994; Volume 2, pp. 443-457.

14. Mackintosh, N.J. IQ and Human Intelligence; Oxford University Press: Oxford, UK, 1998.

15. Cattell, R.B. Abilities: Their Structure, Growth and Action; Houghton-Mifflin: Boston, MA, USA, 1971.

16. Sternberg, R.J. Beyond IQ: A Triarchic Theory of Human Intelligence; Cambridge University Press: New York, NY, USA, 1985.

17. Sternberg, R.J. The Triarchic Mind: A New Theory of Human Intelligence; Viking: New York, NY, USA, 1988.

18. Li, R. A Theory of Conceptual Intelligence: Thinking, Learning, Creativity and Giftedness; Praeger: Westport, CT, USA, 1996.

19. Sternberg, R. J., Ed., Handbook of Creativity. New York: Cambridge University Press, 1999.

20. Intelligence and its measurement: A symposium. J. Educ. Psychol. 1921, 12, 123-147, 195-216, 271-275.

21. Boas. Handbook of American Indian Languages. Available online: http://www.archive.org/download/handbookofameric03boas/handbookofameric03boas.epub (accessed on 15 August 2012).

22. Wober, M. Towards an understanding of the Kiganda concept of intelligence. In Culture and Cognition: Readings in Cross-Cultural Psychology; Berry J.W., Dasen, P.R., Eds.; Methuen: London, UK, 1974; pp. 261-280.

23. Berry, J.W. Cross-cultural variations in intelligence. In Encyclopaedia of Human Intelligence; Sternberg, R.J., Ed.; Macmillan: New York, NY, USA, 1994; pp. 316-322.

24. Anastasi, A. What counsellors should know about the use and interpretation of psychological tests. J. Couns. Dev. 1992, 70, 610-615.

25. Das, J.P. Eastern views of intelligence. In Encyclopaedia of Human Intelligence; Sternberg, R.J., Ed.; Macmillan: New York, NY, USA, 1994; Volume 2, pp.387-391.

26. Byong-ik, K. Confucianism in contemporary Korea. In Confucian Traditions in East Asian Modernity: Moral Education and Economic Culture in Japan and the four other Mini-Dragons; Wei-Ming, T., Ed.; Harvard University Press: Cambridge, UK, 1994; pp. 191-201.

27. Chen, L.F. The Confucian Way; Commercial Press: Taipei China, 1972. 
28. McLean, M. Educational Traditions Compared; David Fulton: London, UK, 1995.

29. Ministry of Education Korea. Education Report; Ministry Press: Seoul, South Korea, 2002.

30. Quah, S.T. Singapore's Model of Development: Is It Transferable? In Behind East Asian Growth: The Political and Social Foundations of Prosperity; Rowen, H.S., Ed.; Routledge: London, UK, 1998; pp. 105-125.

31. Nevo, B.; Khader, A. Cross-cultural, gender and age-differences in Singaporean mothers' conceptions of their children's intelligence. J. Soc. Psychol. 1995, 135, 509-517.

32. Chen, M.J.; Chen, H.C. Concepts of intelligence: A comparison of Chinese graduates from Chinese and English schools in Hong Kong. Int. J. Psychol. 1988, 223, 471-487.

33. Zhang, H.; Wu, Z. People's conceptions of intelligence: A study of Beijing residents' conceptions of intelligence. Sci. Psychol. 1994, 17, 65-69.

34. Yang, S.Y.; Sternberg, R.J. Taiwanese-Chinese people's conceptions of intelligence. Intelligence 1997, 25, 21-37.

35. Gardner, H. Multiple Intelligences: The Theory in Practice; Basic Books: New York, NY, USA, 1983.

36. Ogbu, J.U. Human intelligence testing. A cultural-ecological perspective. Natl. Forum A J. Phi Kappa Phi 1988, 66, 23-49.

37. Vernon, P.E. Intelligence and Cultural Environment; Metheun: London, UK, 1969.

38. Faria, L.; Fontaine, A.M. Adolescents' personal conceptions of intelligence. Eur. J. Psychol. Educ. 1997, 12, 51-61.

39. Raty, H.; Snellman, L. Does gender make a difference? Common sense conceptions of intelligence. Soc. Behav. Personal. 1992, 20, 23-34.

40. Sternberg, R.J.; Conway, B.E.; Ketron, J.L.; Bernstein, M. People's conceptions of intelligence. J. Personal. Soc. Psychol. 1981, 41, 37-55.

41. Berg, C.; Sternberg, R. Adults' conceptions of intelligence across the adult life span. Psychol. Aging 1992, 7, 221-231.

42. Serpell, R. Strategies for investigating intelligence in its cultural context. Quart. Newsl. Lab. Comp. Hum. Dev. 1976, 3, 11-15.

43. Serpell, R. Estimates of intelligence in a rural community of eastern Zambia. In Human Developmental Research Unit Reports, no. 25; University of Zambia: Lusaka, Zambia, 1974.

44. Sternberg, R.J.; Nokes, K.; Geissler, P.W.; Prince, R.; Okatcha, F.; Bundy, D.A.; Grigorenko, E.L. The relationship between academic and practical intelligence: A case study in Kenya. Intelligence 2001, 29, 401-418.

45. Super, C.M. Infants' social experience and attention to discrepant facial masks. Infant Behav. Dev. 1982, 5, 234-239.

46. Jensen, A.R. Bias in Mental Testing; The Free Press: New York, NY, USA, 1980.

47. Greenfield, P.M. The cultural evolution of IQ. In The Rising Curve: Long-Term Gains in IQ and Related Measures; Neisser, U., Ed.; American Psychological Association: Washington, DC, USA, 1998; pp. 81-123.

48. Anastasi, A. Differential Psychology, 4th ed.; Macmillan: New York, NY, USA, 1981.

49. Scarr, S. Race, Social Class and Individual Differences in IQ: New Studies of Old Issues; Eralbum: Hillsdale, NJ, USA, 1981. 
50. Scarr, S. Psychological science in the public arena: Three cases of dubious influence. Scand. J. Psychol. 1994, 36, 164-188.

51. Serpell, R. The Significance of Schooling: Life-Journeys in an African Society; Cambridge University Press: Cambridge, UK, 1993.

52. Gordon, R.A. SES vs. IQ in the Race-IQ Delinquency Model. Int. J. Sociol. Soc. Policy 1987, 7, $30-96$.

53. Reynolds, C.R. Test bias in the assessment of intelligence and personality. In The International Handbook of Personality and Intelligence; Zeidner, M., Ed.; Plenum Press: New York, NY, USA, 1995; pp. 545-573.

54. Anastasi, A. Intelligence as a quality of behavior. In What is Intelligence? Contemporary Viewpoints on Its Nature and Definition; Sternberg, R.J., Detterman, D.K., Eds.; Ablex: Norwood, NJ, USA, 1986; pp. 19-21.

55. Anderson, M. Intelligence and Development: A Cognitive Theory; Blackwell: Oxford, UK, 1992.

56. Scribner, S. Thinking in action: Some characteristics of practical thought. In Practical Intelligence: Nature and Origin of Competence in the Everday World; Sternberg, R.J., Wagner, R.K., Eds.; Cambridge University Press: New York, NY, USA, 1986; pp. 13-30.

(C) 2014 by E.A. Cocodia; licensee MDPI, Basel, Switzerland. This article is an open access article distributed under the terms and conditions of the Creative Commons Attribution license (http://creativecommons.org/licenses/by/4.0/). 